\title{
Patterns of failure in head and neck cancer patients treated with intensity modulated radiation therapy: editorial response
}

\author{
Jonathan E. Leeman, Nancy Lee, Nadeem Riaz \\ Department of Radiation Oncology, Memorial Sloan Kettering Cancer Center, New York, NY 10065, USA \\ Correspondence to: Nadeem Riaz, MD. Memorial Sloan Kettering Cancer Center, Department of Radiation Oncology, 1275 York Ave., New York, NY \\ 10065, USA. Email: riazn@mskcc.org. \\ Response to: van der Veen J, Nuyts S. Intensity modulated radiotherapy for head-and-neck cancer: discussing safety of modern radiation techniques. \\ Transl Cancer Res 2017;6:S1043-8.
}

Submitted Sep 18, 2017. Accepted for publication Sep 28, 2017.

doi: $10.21037 /$ tcr.2017.10.04

View this article at: http://dx.doi.org/10.21037/tcr.2017.10.04

We thank Dr. van der Veen and Dr. Nuyts for their thoughtful discussion and commentary on our recent manuscript as well as placing our results in the broader context of the evolution of target delineation and dosing regimens in head and neck radiotherapy. We herein provide additional clarification to address their comments.

The authors requested additional detail regarding the patterns of treatment failure across the spectrum of our cohort of 1,000 head and neck cancer (HNC) patients who were treated with intensity modulated radiation therapy as part of definitive treatment (1). For oropharynx, larynx and hypopharynx primaries, $40-50 \%$ of failures occurred as isolated locoregional failures, with the remaining failures occurring as isolated distant failure or synchronous locoregional and distant failures. However, for oral cavity cancers (OCC), 29/45 (64.4\%) treatment failures occurred as isolated locoregional failure. This predilection for locoregional failure occurred despite the fact that, as mentioned, $41 \%$ of OCC patients were treated with trimodality therapy. A more detailed summary of the patterns of failure across various head and neck sub-sites are provided in the supplemental material of our manuscript in eFigure 2.

Regarding the patterns of failure for the 78 patients who experienced regional failure as a first site of relapse- 37 (47\%) were isolated regional failures, 19 (24\%) occurred synchronously with local failure, 12 (15\%) occurred synchronously with distant failure and 10 (13\%) occurred synchronously with both local and distant failure. Of the 12 regional failures from OCC primaries, 8 (53\%) occurred as isolated regional failure, 3 (20\%) occurred synchronously with local failure, 3 occurred synchronously with distant failure (20\%) and 1 occurred synchronously with local and distant failure (7\%).

These findings again solidify our observation that OCC cancers demonstrate a unique pattern of predominantly locoregional failure, though in patients who do develop metastatic disease from OCC, survival is very poor (median 3.9 months). As summarized, the majority of regional failures, and particularly those from OCC, within our cohort occurred as isolated locoregional failures without distant metastasis. This combined with our finding of a predominantly locoregional pattern of failure in OCC leads us to believe that personalization of therapy in locally advanced OCC foremost requires tailoring of local therapy. This should involve particular attention to optimizing radiation fields, as evidenced by our finding of unexpected OCC failures occurring within superficial anterior cervical nodal basins, as well as personalization of radiation dose and exploration of novel radiosensitizing agents. Because only the minority of OCC failures occur distantly, intensification of systemic therapy regimens, such as with use of induction chemotherapy, introduces significant morbidity and is likely to be of limited benefit in this population. We believe that the unique clinical behavior of OCC suggests a distinct biology that remains to be explored further as well as a need for clinical trials to investigate approaches for intensification of locoregional therapy in this high-risk population. 
We agree with van der Veen et al.'s assessment of the limitations of our work including the single institution nature of the study which may not be reflective of universal practice. However, by providing information on outcomes within a cohort that was treated in a largely uniform manner with minimal error in target delineation, we hope that this work provides more accurate data regarding relapses due to truly radio- and chemo-resistant disease and suggests which areas in locoregional disease control require new therapies and which areas may require improved quality assurance. These data may therefore better inform and direct clinical trial design as the confounder of major variation in treatment technique that is present within the context of multicenter trials or pooled analyses is minimized $(2,3)$. Lastly, we concur with van der Veen et al.'s assessments that our data supporting low rates of elective nodal failure suggest that both the volume and doses to these elective regions may be de-escalated. Possible approaches include dose de-escalation as Nuyts et al. have done (4), whereas others have suggested removal of certain volumes in the setting of response to induction chemotherapy (5). We believe this remains an open area of investigation that can be informed by our data and others.

\section{Acknowledgments}

Funding: None.

\section{Footnote}

Provenance and Peer Review: This article was commissioned and reviewed by the Section Editor Dr. San-Gang Wu (Department of Radiation Oncology, Xiamen Cancer Center, The First Affiliated Hospital of Xiamen University, Xiamen, China).

Conflicts of Interest: All authors have completed the ICMJE uniform disclosure form (available at http://dx.doi. org/10.21037/tcr.2017.10.04). The authors have no conflicts of interest to declare.

Ethical Statement: The authors are accountable for all aspects of the work in ensuring that questions related to the accuracy or integrity of any part of the work are appropriately investigated and resolved.

Open Access Statement: This is an Open Access article distributed in accordance with the Creative Commons Attribution-NonCommercial-NoDerivs 4.0 International License (CC BY-NC-ND 4.0), which permits the noncommercial replication and distribution of the article with the strict proviso that no changes or edits are made and the original work is properly cited (including links to both the formal publication through the relevant DOI and the license). See: https://creativecommons.org/licenses/by-nc-nd/4.0/.

\section{References}

1. Leeman JE, Li JG, Pei X, et al. Patterns of Treatment Failure and Postrecurrence Outcomes Among Patients With Locally Advanced Head and Neck Squamous Cell Carcinoma After Chemoradiotherapy Using Modern Radiation Techniques. JAMA Oncol 2017. [Epub ahead of print].

2. Peters LJ, O'Sullivan B, Giralt J, et al. Critical impact of radiotherapy protocol compliance and quality in the treatment of advanced head and neck cancer: results from TROG 02.02. J Clin Oncol 2010;28:2996-3001.

3. Boero IJ, Paravati AJ, Xu B, et al. Importance of Radiation Oncologist Experience Among Patients With Head-andNeck Cancer Treated With Intensity-Modulated Radiation Therapy. J Clin Oncol 2016;34:684-90.

4. Nevens D, Duprez F, Daisne JF, et al. Recurrence patterns after a decreased dose of $40 \mathrm{~Gy}$ to the elective treated neck in head and neck cancer. Radiother Oncol 2017;123:419-23.

5. Villaflor VM, Melotek JM, Karrison TG, et al. Responseadapted volume de-escalation (RAVD) in locally advanced head and neck cancer. Ann Oncol 2016;27:908-13.
Cite this article as: Leeman JE, Lee N, Riaz N. Patterns of failure in head and neck cancer patients treated with intensity modulated radiation therapy: editorial response. Transl Cancer Res 2017;6(Suppl 7):S1299-S1300. doi: 10.21037/tcr.2017.10.04 